\title{
PENGARUH POTONGAN HARGA (DISCOUNT) \\ TERHADAP PEMBELIAN TIDAK TERENCANA (IMPULSE BUYING) (studi pada pengunjung Matahari Department Store Johar Plaza Jember)
}

\author{
Indra Bayu Baskara \\ Department of Management FEB UMM \\ Email: indrabayubaskara@gmail.com
}

\begin{abstract}
The purpose of this research was to analyze the response of impulse buying, response to discount on Matahari Department store and the effect of discount on impulse buying on visitors. The population in were the visitors at Matahari Department Store, the number of samples 100 visitors who were collected by using purposive sampling technique. The analysis technique was descriptive analysis and the simple linear regression. The result of descriptive analysis shows that the response of impulse buying was positive and the response of discount was also positive. The result of simple linear regression show that impulse buying was influenced by discounted price (discount) on Matahari Department Store. The positive results tend to be weak indicated by the results of adjusted $R$-square. This mean that the impulse buying in Matahari Department Store was also influenced by other variables outside of this research.
\end{abstract}

Keywords: Price, Discount, impulse buying.

\section{PENDAHULUAN}

Konsumen memiliki berbagai tingkah laku yang berbeda dan sering berubah dalam memutuskan suatu pembelian. Dilihat dari segi perencanaan, pembelian konsumen bisa dikategorikan ke dalam pembelian terencana (planned purchasing) dan pembelian tak terencana (unplanned purchasing). Pembelian terencana adalah perilaku pembelian dimana keputusan tentang item yang akan dibeli telah diambil sebelum konsumen masuk ke dalam toko (Dony, 2007).

Impulse Buying didefinisikan sebagai tindakan membeli yang sebelumnya tidak diakui secara sadar sebagai hasil dari suatu pertimbangan atau niat membeli yang terbentuk sebelum memasuki toko (Mowen dan Minor 2002:10).

Perilaku belanja impulse terjadi di Indonesia, terlihat dari hasil survei yang dilakukan oleh AC Nielsen dalam majalah Marketing 5 (2009) terhadap pembelanja disebagian besar supermarket dan hypermarket dibeberapa kota besar seperti Bandung, Jakarta dan Surabaya. Berdasarkan survey tersebut sekitar 85 persen pembelanja kadang-kadang atau selalu membeli produk tidak direncanakan, sedangkan jumlah pembelanja yang melakukan pembelian sesuai dengan rencana dan tidak terdorong untuk membeli item tambahan hanya 
berkisar 15 persen saja. Hal ini bermakna bahwa masyarakat Indonesia adalah masyarakat yang suka belanja dengan tidak direncanakan sebelumnya.

Terdapat faktor yang mempengaruhi impulse buying diantaranya yang diambil dalam penelitian ini adalah discount, dalam era persaingan yang ketat seperti ini, perusahaan harus memperhatikan faktor harga, karena besar kecilnya harga sangat mempengaruhi kemampuan bersaing suatu perusahaan dan mempengaruhi konsumen untuk membeli produknya. Menurut Sutisna (2002:303) tujuan pemberian potongan harga adalah Mendorong pembelian dalam jumlah besar, mendorong agar pembelian dapat dilakukan dengan kontan atau waktu yang lebih pendek (impulse buying), dan mengikat pelanggan agar tidak berpindah ke perusahaan lain. Hal ini umumnya dipakai perusahaan untuk membujuk pengguna lama agar membeli lebih banyak, mendorong pengguna produk baru atau yang meyakinkan konsumen untuk mencoba produk yang telah lama ada. Selain itu potongan harga cukup mendapat respon yang cepat dari konsumen, hal ini dapat dilihat antusias konsumen apabila ada potongan harga seperti di departemen store konsumen lebih memperhatikan produk produk yang diberi potongan harga dari pada produk-produk dengan harga normal.

Fenomena yang terjadi zaman modern seperti sekarang ini berjalan jalan dipusat perbelanjaan atau mall seakan sudah menjadi life style tidak hanya bagi kalangan anak muda atau remaja tetapi sudah menjadi kebiasaan bagi orang yang sudah mempunyai keluarga sekalipun. Di dalam pusat perbelanjaan selain suasana yang nyaman untuk berjalan bersama teman atau keluarga, disamping itu pada pusat perbelanjaan banyak ditawarkan potongan harga yang menarik terhadap macam macam produk yang dijual dan kerapian setiap penataan produk yang dijual dipusat perbelanjaan sehingga konsumen dapat melihat dengan mudah produk produk yang dijual. Dalam pusat perbelanjaan juga banyak pusat permainan baik untuk anak-anak maupun dewasa, dari awalnya hanya ingin jalan jalan dan bermain setelah melihat banyak potongan harga yang menarik, rapinya penataan produk, dan suasana nyaman maka konsumen tertarik untuk membeli.

Potongan harga (discount) merupakan strategi yang dilakukan perusahaan dengan memberikan pengurangan harga dari harga yang sudah ditetapkan untuk menciptakan impulse buying demi meningkatkan penjualan produk atau jasa. Seperti yang terdapat dalam jurnal "Impulse Purchasing as a Purchasing Behaviour and Research on Karaman" (Selda Basaran Alagoz, International Research Journal of Finance and Economics, Issue 66, 2011) dalam hasil penelitian mereka membuktikan bahwa produk yang disount dapat mengindukasi pembelian secara Impulse.

Matahari sebagai salah satu Department store yang selalu mengadakan program promosi untuk menarik minat konsumen agar melakukan impulse buying. Bellenger, et al (1978), berpendapat bahwa seluruh pembelian pada Department Store dilakukan secara 
impulse.

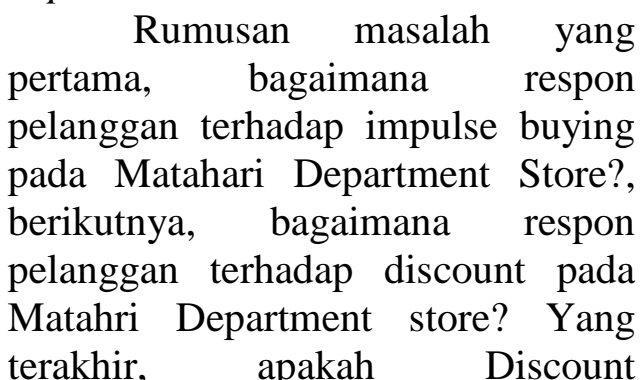
mempengaruhi impulse buying pada matahari department store?

Tujuan penelitian ini adalah untuk mengetahui dan menganalisa respon Impulse buying pada Matahari Department Store, mengetahui dan menganalisa respon Discount pada Mathari Department Store, menguji pengaruh discount terhadap impulse buying pada Matahari Department Store.

Secara teoritis, penelitian ini dapat bermanfaat untuk pengembangan ilmu pengetahuan tentang perilaku konsumen mengenai impulse buying. Penelitian ini dapat bermanfaat untuk pengetahuan tentang discount sebagai bahan untuk penelitian selanjutnya.

Dapat di jadikan acuan untuk diteliti lebih lanjut dengan menambah variable lain selain diskon yang dapat mempengaruhi keputusan impulse buying.

Penelitian ini memberikan manfaat bagi perusahaan Matahari Departmen Store atau pelaku usaha lainnya berupa informasi yang dapat digunakan sebagai bahan evaluasi terhadap upaya yang telah ditempuh perusahaan dalam proses promosi melalui Discount yang berpengaruh terhadap Impulse buying.

Perusahaan yang menjual produk di Matahari Departmen Store sebagai informasi perilaku konsumen terutama perilaku pembelian yang tidak direncanakan (impulse buying) untuk merancang strategi pemasaran produknya.

\section{TINJAUAN PUSTAKA}

Secara umum harga mempunyai peranan penentu dalam pilihan konsumen atau pembeli. Hal ini masih berlaku di Negara miskin, diantaranya kelompok menengah ke bawah dan untuk jenis produk komuditi.

Dari sudut pandang konsumen, harga sering kali digunakan sebagi indikator nilai bagaimana harga tersebut dihubungkan dengan manfaat yang dirasakan atas suatu barang atau jasa, Fandy Tjiptono (1997:147).

Maka berdasarkan teori diatas dapat disimpulkan yang dimaksud dengan harga adalah jumlah yang harus dibayarkan oleh konsumen yang dianggap layak untuk memperoleh atau memiliki produk dimana besarnya ditetapkan oleh perusahaan atau penjual.

Menurut Sutisna, dalam bukunya yang berjudul Perilaku Konsumen dan Komunikasi Pemasaran (2001) diskon atau potongan harga adalah pengurangan harga produk dari harga normal dalam periode tertentu.

Sedangkan yang menjadi dimensi diskon yaitu: Besarnya potongan harga yang di berikan, masa potongan harga yang di berikan, jenis produk yang mendapat potongan.

Impulse Buying atau juga disebut unplaned purchasing didefinisikan sebagai tindakan membeli yang sebelumnya tidak diakui secara sadar sebagai hasil dari suatu pertimbangan atau niat membeli yang terbentuk sebelum memasuki 
toko (Mowen dan Minor 2002:10). Verplanken \& Herabadi (2001) mengatakan terdapat dua elemen penting dalam impulse buying yaitu yang pertama, kognitif berarti tidak mempertimbangan harga dan kegunaan suatu produk, tidak melakukan evaluasi terhadap suatu pembelian produk, tidak melakukan perbandingan produk yang akan dibeli dengan produk yang mungkin lebih berguna, yang kedua, emosional yaitu timbulnya dorongan perasaan untuk segera melakukan pembelian dan timbul perasaan senang dan puas setelah melakukan pembelian.

Seperti yang terdapat dalam jurnal "Impulse Purchasing as a Purchasing Behaviour and Research on Karaman" (Selda Basaran Alagoz, International Research Journal of Finance and Economics, Issue 66, 2011) dalam hasil penelitian mereka membuktikan bahwa produk yang discount dapat mengindukasi pembelian secara Impulse atau pembelian tidak terencana.

Berdasarkan teori teori yang telah di paparkan di atas maka dapa di susun kerangka konsep sebagai berikut:

Gambar 1. Kerangka Konsep

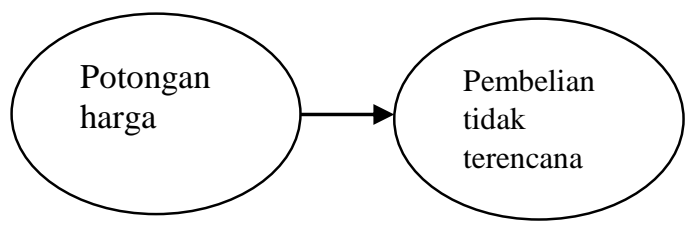

Hipotesis dalam penelitian ini $H_{1}$ : Potongan harga berpengaruh signifikan dan positif terhadap pembelian tidak terencana.

\section{METODOLOGI PENELITIAN}

Penelitian ini menggunakan metode survey dilakukan di Matahari Departmen Store Johar Plaza Jalan Diponegoro Jember. Lokasi tersebut dipilih karena kajian atas lokasi penelitian dapat menjawab permasalahan pokok dari studi ini secara lebih spesifik.

Sampel dalam penelitian ini dari responden yang mengunjungi Matahari Departemen Store Jember. Dengan menggunakan teknik Purposive Sampling, yaitu teknik sampling yang satuan samplingnya dipilih berdasarkan pertimbangan tertentu dengan tujuan untuk memperoleh satuan sampling yang memiliki karakteristik atau kriteria yang dikehendaki dalam pengambilan sampel sebanyak 100 orang.

Teknik pengumpulan data yang di gunakan adalah menggunakan kuisioner. Sedangkan Teknik pengukuran data menggunakan skala likert. Menurut Luck David dalam Widayat (2004: 76), bentuk asal dari skala likert memiliki lima kategori. Apabila diranking, maka akan memiliki susunan yang dimulai dari sangat tidak setuju, tidak setuju, ragu, setuju dan sangat setuju. Penilaian jawaban dari responden akan dilakukan sebagai berikut: menjawab sangat tidak setuju skor 1 , menjawab tidak setuju skor 2, menjawab ragu skor 3, menjawab setuju skor 4 dan menjawab sangat setuju skor 5 .

Definisi operasional variable dalam penelitian ini yang uraikan yaitu, Variabel bebas yaitu potongan harga $(X)$ : Pengurangan harga produk dari harga normal dalam periode tertentu. Indikatornya besarnya 
potongan harga yaitu ukuran besar atau kecilnya potongan harga yang diberlakukan terhadap suatu produk, lalu masa potongan harga yitu dimana waktu atau rentang waktu potongan harga di berikan, yang ketiga jenis produk yang dapat potongan harga yitu tentang jenis produk apa yang akan mendapat potongan harga.

Sedangkan variabel terikat yaitu pembelian tidak terencana: Suatu tindakan pembelian yang dibuat tanpa direncanakan sebelumnya atau keputusan pembelian dilakukan pada saat berada didalam toko. Indikatornya kognitif berarti tidak mempertimbangkan harga dan kegunaan suatu produk, tidak melakukan evaluasi terhadap suatu pembelian produk dan tidak melakukan perbandingan produk yang akan di beli dengan produk yang lebih berguna. Yang kedua, emosional. Yaitu timbulnya dorongan perasaan untuk segera melakukan pembelian, timbulnya perasaan senang dan puas setelah melakukan pembelian.

Analisis data menggunakan analisi deskriptif dan analisis regresi sederhana. Analisis deskriptif digunakan untuk mendeskripsikan atau memberi gambaran terhadap obyek yang diteliti melalui data sample sebagaimana adanya tanpa membuat kesimpulan yang berlaku untuk umum (Sugiyono, 2002:37). Persamaan regresi linier sederhana :

$$
\mathrm{Y}=\mathrm{a}+\mathrm{bx}+\mathrm{e}
$$

\section{HASIL PENELITIAN DAN PEMBAHASAN}

Identitas responden dari penelitian ini adalah pengunjung yang melakukan pembelian di Matahari
Department Store Jember. Berikut ini merupakan deskripsi identitas responden penelitian yang dikelompokkan berdasarkan jenis kelamin, usia dan pekerjaan.

Tabel 1. Karakteristik Responden Berdasarkan Jenis Kelamin

\begin{tabular}{llll}
\hline No & Jenis Kelamin & $\sum$ & \% \\
\hline $\mathbf{1}$ & Laki-laki & 27 & $27 \%$ \\
$\mathbf{2}$ & Perempuan & 73 & $73 \%$ \\
& Total & 100 & $100 \%$ \\
\hline
\end{tabular}

Berdasarkan tabel diatas diketahui bahwa dari 100 responden, 73 responden atau $73 \%$ adalah perempuan. Hal ini artinya responden perempuan cenderung lebih senang dan emosional didalam berbelanja, apalagi jika melihat display potongan harga atau bonus-bonus yang ditawarkan suatu produk, maka perempuan akan lebih senang berlama-lama untuk berbelanja. Walaupun begitu, tetap saja Matahari Department store juga sebaiknya memperhatikan konsumen laki-laki dan merancang strategi diskon yang menarik sehingga diharapkan pembelian tidak terencana dapat terjadi.

Tabel 2. Karakteristik Responden Berdasarkan Usia

\begin{tabular}{llll}
\hline No & Usia & $\sum$ & \% \\
\hline $\mathbf{1}$ & $15-22$ & 29 & $29 \%$ \\
$\mathbf{2}$ & $23-29$ & 24 & $24 \%$ \\
$\mathbf{3}$ & $30-36$ & 27 & $27 \%$ \\
$\mathbf{4}$ & $37-43$ & 12 & $12 \%$ \\
$\mathbf{5}$ & $44-50$ & 8 & $8 \%$ \\
& Total & 100 & $100 \%$ \\
\hline
\end{tabular}

Pada Tabel di atas dapat diketahui sebagian besar responden yang pernah melakukan pembelian di 
Matahari Departement Store adalah pada usia 15-22 tahun, yaitu sebanyak 29 responden sedangkan paling sedikit 44-50 tahun sebesar 8 responden. Dari penjabaran data di atas, dapat diartikan bahwa pada usia 15 - 22 tahun yang merupakan usia remaja ( siswa - mahasiswa) berkaitan dengan tema penelitian cenderung lebih besar melakukan pembelian secara tidak terencana dan pada kenyataannya barang yang dijual pada Matahari Departement Store kebanyakan barang fashion yang sangat digandrungi para remaja, sedangkan prosentase paling kecil yaitu $8 \%$, terjadi pada usia $44-50$ tahun yang merupakan usia senja atau lebih tua mereka cenderung lebih dewasa dan mempertimbangkan banyak hal dalam berbelanja di Matahari Departement store.

Tabel 3. Karakteristik Responden Berdasarkan Pekerjaan

\begin{tabular}{|c|c|c|c|}
\hline No & Pekerjaan & $\sum$ & $\%$ \\
\hline 1 & $\begin{array}{l}\text { Pegawai } \\
\text { negeri }\end{array}$ & 12 & $12 \%$ \\
\hline 2 & Wiraswasta & 3 & $3 \%$ \\
\hline 3 & $\begin{array}{l}\text { Karyawan } \\
\text { swasta }\end{array}$ & 22 & $19 \%$ \\
\hline 4 & Lain - lain & 21 & $21 \%$ \\
\hline \multirow[t]{2}{*}{5} & $\begin{array}{l}\text { Tidak } \\
\text { bekerja }\end{array}$ & 42 & $45 \%$ \\
\hline & Total & 100 & $100 \%$ \\
\hline
\end{tabular}

Pada tabel diketahui sebagian besar responden yang melakukan pembelian di Matahari Departement Store adalah responden yang tidak memiliki pekerjaan/tidak berpenghasilan (siswa/mahasiswa dan ibu rumah tangga) yaitu sebanyak 42 orang dengan presentase $42 \%$. Tingginya prosentase atau jumlah responden yang tidak memiliki penghasilan sendiri, artinya mereka dalam hal berbelanja di Matahari Deparrtement Store, mereka seakan emosional karena uang yang mereka dapatkan masih hasil dari pemberian orang tua atau suami mereka, sehingga lebih mudah menghabiskan uang. Dalam hal ini dapat diartikan siswa/mahasiswa dan ibu rumah tangga berkaitan dengan tema penelitian lebih cenderung emosional dalam berbelanja selain itu mereka juga sering nongkrong atau menemani anak mereka di Mall.

Analisa ini akan memberikan hasil apakah antara variabel-variabel yang sedang diteliti atau sedang dianalisis terdapat hubungan, baik saling berhubungan, saling mempengaruhi dan seberapa besar tingkat hubungannya.

Tabel 4. Model Summary

\begin{tabular}{ccccc}
\hline Model & $\mathbf{R}$ & $\begin{array}{c}\mathbf{R} \\
\text { Square }\end{array}$ & $\begin{array}{c}\text { Adjusted } \\
\mathbf{R}\end{array}$ & $\begin{array}{c}\text { Std. Eror } \\
\text { of The } \\
\text { Estimate }\end{array}$ \\
\hline $\mathbf{1}$ & $\dot{72^{\mathrm{a}}}$ & 492 & .487 & 4.0268 \\
& & & \\
\hline
\end{tabular}

Berdasarkan table 4 diketahui bahwa angka adjust $\mathrm{R}$ square adalah 0.487 . Angka adjust $\mathrm{R}$ square juga disebut koefisien determinasi adalah 0.487 atau $48,7 \%$. Artinya dari perolehan ini dapat ditafsirkan bahwa $48,7 \%$ dari pembelian tidak terencana yang terjadi di Matahari Department Store dapat dijelaskan menggunakan potongan harga. Sedangkan sisanya sebesar 51,3\% dapat dijelaskan oleh variabel lain diluar variabel potongan harga tersebut yang tidak di masukkan dalam penelitian ini.

Besarnya nilai koefisien determinasi yang telah diketahui sebesar 48,7\% menunjukkan bahwa hasil tersebut cukup lemah dalam 
mewakili penelitian ini. Hasil ini menunjukkan potongan harga pada Matahari Departement Store bermakna positif tetapi dilihat dari posisi interprestasinya kategori cenderung cukup atau sedang. Standart Error Estimate (SEE) sebesar 4,0268 Artinya semakin kecil nilai SEE maka akan membuat model regresi semakin tepat dalam memprediksi variabel dependen.

Tabel 5. Coefficients ${ }^{\mathrm{a}}$

\begin{tabular}{|c|c|c|c|c|c|}
\hline \multirow{2}{*}{ Model } & \multicolumn{2}{|c|}{$\begin{array}{l}\text { U. Std. } \\
\text { Coef. }\end{array}$} & $\begin{array}{c}\text { Std. } \\
\text { Coef } \\
\\
\end{array}$ & \multirow[t]{2}{*}{$\begin{array}{c}t \\
\text { hitu } \\
\text { ng } \\
\end{array}$} & \multirow[t]{2}{*}{$\underset{t}{\text { Sig }}$} \\
\hline & B & $\begin{array}{c}\text { Std. } \\
\text { erro } \\
r\end{array}$ & Beta & & \\
\hline (Consta & 6.83 & 1.33 & & 5.0 & .0 \\
\hline nt) & 3 & 60 & & 25 & 00 \\
\hline $\mathbf{X}$ & .949 & .097 & .702 & $\begin{array}{r}9.7 \\
45\end{array}$ & $\begin{array}{r}.0 \\
00\end{array}$ \\
\hline
\end{tabular}

Pada tabel diatas, diperoleh persamaan regresi dengan unstandarized standardized coefficients sebagai berikut:

$$
\mathrm{Y}=6,833+0,949(\mathrm{X})+4,0268(\mathrm{e})
$$

Dari persamaan garis regresi linier sederhana, maka dapat ditarik kesimpulan bahwa, $\mathrm{a}=6,833$ merupakan nilai konstanta nilai konstanta ini menunjukkan besarnya nilai variable pembelian tidak terencana pada Matahari department Store. Jika variable sama dengan nol atau konstan (tidak ada perubahan).

$\mathrm{b}=0,949$ merupakan arah koefisien variable potongan harga $(\mathrm{X})$ yang di lakukan di Matahari Department Store mempengaruhi pembelian tidak terencana pada konsumen Matahari Department store, artinya dimensi variable potongan harga $(\mathrm{X})$ searah (positif) sebesar 0,949 terhadap pembelian tidak terencana.

$$
\mathrm{e}=4,0268 \text { merupakan nilai }
$$

error. Dari persamaan tersebut terlihat bahwa pengaruh potongan harga adalah searah atau positif, dalam hal ini artinya semakin positif atau besar respon potongan harga pada Matahari Department Store maka akan semakin besar juga pengunjung dalam melakukan pembelian tidak terencana.

Untuk menguji hipotesis pertama maka digunakan uji $\mathrm{F}$ yaitu untuk menguji variabel-variabel bebas (X) secara bersama-sama (serempak) terhadap variabel terikat. Pengujian ini dilakukan dengan membandingkan nilai hitung $\mathrm{F}$ hitung dengan $\mathrm{F}_{\text {tabel. }}$. Hasil pengujian adalah hitung $\mathrm{F}$ menunjukkan nilai sebesar 94,967 (signifikansi $\mathrm{p}=0,000$ ).

Jadi hitung $\mathrm{F}$ hitung $\geq \mathrm{F}$ tabel $(94,967 \geq 3,09)$ atau Sig F $<5 \%$ $(0,000<0,05)$. Artinya dapat diketahui bahwa variabel Potongan harga (X) secara simultan berpengaruh signifikan terhadap pembelian tidak terencana (Y). Rekapitulasi Uji F

Tabel 6. ANNOVA ${ }^{\mathrm{a}}$

\begin{tabular}{lcrrrr}
\hline Model & $\begin{array}{c}\text { Sum } \\
\text { of } \\
\text { Squar } \\
\text { es }\end{array}$ & $\begin{array}{c}\text { Df Mean } \\
\text { Squa } \\
\text { re }\end{array}$ & F & Sig \\
& & & \\
\hline Regresi & 1539. & 1 & 1539. & 94.9 & .00 \\
on & 908 & 908 & 67 & 0 \\
Residu & 1589. & 98 & 16.21 & & \\
al & 082 & 5 & & \\
Total & 3128.99 & & & \\
& 990 & & & & \\
\hline
\end{tabular}

a .Dependent Variable: Y

b.Predictors: (Constanst), X 


\begin{abstract}
Berdasarkan hasil analisis yang telah dilakukan, dapat memberikan informasi mengenai pengaruh dari variabel potongan harga $(\mathrm{X})$ terhadap pembelian tidak terencana $(\mathrm{Y})$.

Dari hasil analisis deskriptif rentang skala deskripsi jawaban responden terhadap variabel penelitian, skor rata-rata variabel potongan harga menunjukkan 3,33 sedangkan pada skor rata-rata variabel pembelian tidak terencana menunjukkan 3,24.
\end{abstract}

Dari hasil rentang skala deskripsi jawaban responden itu diketahui, bahwa respon potongan harga dan respon pembelian tidak terencana pada Matahari Department Store positif termasuk dalam kategori sedang dilihat dari nilai interprestasinya.

Dari persamaan regresi terlihat bahwa pengaruh potongan harga adalah searah atau positif, dalam hal ini artinya semakin positif atau besar respon potongan harga pada Matahari Department Store maka akan semakin besar juga pengunjung dalam melakukan pembelian tidak terencana.

Dari hasil uji hipotesis menunjukkan bahwa variabel Potongan harga $(\mathrm{X})$ secara simultan berpengaruh signifikan terhadap pembelian tidak terencana $(\mathrm{Y})$.

\section{SIMPULAN}

Berdasarkan hasil analisis deskriptif dapat diketahui bahwa respon responden terhadap pembelian tidak terencana yang terdiri dari dua elemen kognitif dan emosional, dari kedua elemen pembelian tidak terencana tersebut sama-sama mendapat respon positif dari pengunjung Matahri Department Store.

Berdasarkan hasil analisis deskriptif dapat diketahui bahwa respon responden terhadap potongan harga yang terdiri dari empat indikator besarnya potongan harga yang ditawarkan menarik, waktu potongan tepat pada waktunya, rentang waktu potongan harga terbilang lama dan jenis produk yang mendapat potongan sesuai dengan keinginan konsumen sama sama mendapatkan respon tinggi dari resonden.

Berdasarkan hasil analisis regresi potongan harga berpengaruh positif atau signifikan terhadap pembelian tidak terencana di Matahari Department Store tetapi interprestasi pengaruhnya cenderung cukup atau sedang.

Berdarkan hasil analisis respon atas pembelian tidak terencana, maka dapat di ketahui dari dua elemen penting pembelian tidak terencana atara lain kognitif dan emosional keduanya sama sama mendapat respon positif. Sehingga kedua elemen penting dalam pembelian tidak terencana.

Berdasarkan hasil analisis respon atas potongan harga dari ke empat indikator tersebut dapat digunakan kembali untuk mengetahui dan mengukur respon potongan harga dalam Matahari Department Store atau di Departement Store lainnya.

Pihak Matahari Departement Store dan pelaku usaha lainnya yang menjual produk di Matahari Departement Store dapat menyusun strategi yang tepat dalam menentukan potongan harga yang menarik, waktu yang sesuai, rentang waktu potongan, dan jenis produk yang mendapat 
potongan agar pembelian tidak terencana yang tercipta semakin besar.

\section{DAFTAR PUSTAKA}

Alma, Buchari. 2007. Manajemen Pemasaran dan Pemasaran Jasa. CV Alvabeta: Bandung.

Amstrong, dan Kotler. 2003. Dasardasar Manajemen Pemasaran. Jilid 1. Penerbit PT. Indeks. Jakarta.

Arifianti, Ria. 2006. Pengaruh Promosi Penjualan Terhadap Impulse Buying Pada Hypermart Kota Bandung.

Beatty and Ferrel dalam Strack, 2006 di kutip oleh Fatchur Rohman dalam Peran Nilai Hedonik Konsumsi dan Reaksi Impulsif sebagai Media Pengaruh Faktor Situsional terhadap Keputusan Pembelian Impulsif di Butik Kota Malang. Jurnal Manajemen, Vol. 7 No. 2. Mei 2009:251-261.

Ghozali, Imam. 2005. Analisis Multivariat dengan Program SPSS. Edisi ke-3. Badan Penerbit UNDIP. Semarang.

Kotler, Phillip dan Gary Amstrong. 2008. Prinsip-Prinsip Pemasaran, jilid 1, Penerbit Elangga, Jakarta.

Kotler, Phillip dan Gary Amstrong. 2001. Prinsip-Prinsip Pemasaran, jilid 2, edisi ke-8, Penerbit Elangga, Jakarta.

Kotler, Philip, 1997, Manajemen Pemasaran (Analisis, Perencanaan, Implementasi, dan Kontrol), PT. Prenhallindo, Jakarta.

Kotler, Philip. 2009. Manajemen Pemasaran. Erlangga. Jakarta.
Liang, Y. P., Liang, J. L., dan Duan, Y. S. (2008), Relationship Between Consumer Information Exposure, Product Knowledge, and Impulse Purchasing Behavior: An Empirical Analysis", International Journal of Management, Vol. 25 No. 3, pp. $418-430$

Loudon, D. L., \& Bitta, B. A. J. 1993. Consumer Behavior 4th Edition. New York: Mc Graw Hill. Malhotra, Neresh K. 2009. Riset Pemasaran. Edisi keempat Jilid 1. PT. Indeks Jakarta.

Mowen, John C dan Minor, M. 2002. Perilaku Konsumen Jilid 2, Jakarta: Erlangga

Mudrajat, Kuncoro. 2003. Metode Riset Untuk Bisnis dan ekonomi. Erlangga, Jakarta.

Purjono, 2007, "Berharap dari Impulse Buying." Marketing, Agustus 2007

Rook, Dennis W. dan Robert, J. Fisher. (1995). Normative Influences on Impulsive Buying Behavior. Journal of ConsumerResearch, 22, (Dec), pp. 305-13.

Schifman, leon G \& kanuk, leslie L. (2004), "consumer behavior".8 Edition, New jersey; Pearson-Prentice hall.

Semuel, H. 2005. Respon lingkungan berbelanja sebagai stimulus pembelian tidak terencana pada toko serba ada (toserba): studi kasus carrefour surabaya, Jurnal Manajemen dan Kewirausahaan Vol. 7 No. 2, pp. 152-170.

Semuel, H. 2006. Dampak respon emosi terhadap 
kecenderungan perilaku pembelian impulsif konsumen online dengan sumberdaya yang dikeluarkan dan orientasi belanja sebagai variabel mediasi, Jurnal Manajemen dan Kewirausahaan Vol. 8 No.2, pp. 101-115.

Selda, Basaran Alagoz. "Impulse Purchasing as a Purchasing Behaviour and Research onKaraman", International Research Journal of Finance and Economics, Issue 66, 2011)

Sugiyono. 2010.Metode Penelitian Bisnis. Bandung: Alfabeta.

Suharsimi, Arikunto, 2002. Manajemen Penelitian. Rineka Cipta. Jakarta.

Sutisna, 2001. Perilaku Konsumen dan Komunikasi Pemasaran, Remaja Rosdakarya. Bandung

Sutisna, 2002. Perilaku Konsumen dan Komunikasi Pemasaran, Remaja Rosdakarya.Bandung.

Sutisna, 2003. Perilaku Konsumen dan Komunikasi Pemasaran, cetakan Ketiga, Remaja Rosdakarya. Bandung.
Sutojo, 2001 Menyusun Strategi harga. Edisi empat. Damar Mulia Pustaka. Jakarta.

Tjiptono, Fandy, 2005. Pemasaran Jasa. Edisi Pertama. Bayu Media Publishing. Malang. 2008. Strategi Pemasaran Edisi III. Andi Offset. Jakarta.

Utami, Christina Widya. 2006. Manajemen Ritel. Selemba Empat. Jakarta.

Utami, Christina Widya. 2010. Manajemen Ritel. Salemba Empat. Jakarta.

Yadi Budhisetiawan. 2007. Konsumen Indonesia Sangat Sembrono. Jakarta; Marketing. PFE: Yogyakarta.

Verplanken, Bas dan Herabadi, Astrid. (2001). Individual Differences in Impulse Buying Tendency: Feeling and No Thinking. European Journal of Personality, 15, Special Issue on Personality and Economic Behavior, S71-S83. 